\title{
Morphological Features of Dentition Associated With Unilateral Palatally Impacted Canine Using Cone Beam Computedtomography: An Etiological Study
}

\author{
Omar Okasha ${ }^{1}$; Essam Abdallah²; Tarek Nasr-eldin Yousry ${ }^{3}$
}

\section{ABSTRACT}

Introduction: the aim of this study is to determine the morphological features of dentition associated with unilateral palatally impacted maxillary canine and to predict of the possible local risk factors causing palatal impaction of the maxillary canine.

Materials and Methods: 45 cone beam computer tomography were collected of patients diagnosed with unilateral palatally impacted canines 11 males and 34 females the mean age was $20.38 \pm 4.37$. The maxilla was divided into two for a split mouth design. The following parameters were obtained: The mesiodistal width of each tooth, the crown/root ratio of each tooth, and the volume of the impacted canine compared to the contralateral normally erupting canine, angulation and morphology of the root, Interpremolar and intermolar width of the upper arch and the arch perimeter. The measures were compared between the 2 sides. The data obtained in this study was subjected to Kolmogorov-Smirnov test, McNemar test and Paired $t$-test at $\mathbb{P} \leq 0.05$.

Results: The results showed larger canine volume, narrower interpremolar width and increased crown root ratio of the laterals and canines on the impacted side. There was no statistically significant difference between two sides in the rest of the measurements.
Conclusion: Narrower interpremolar width, increased canine volume, shorter root of lateral incisor and increased length of canine crown are contributing factors for impaction of the canine.

Keywords: impacted canines, cone beam, canine volume, maxillary dentition morphology.

aMaster student, Orthodontic Department, Faculty of Dentistry, University of Alexandria.

6 Professor of orthodontics, Orthodontic Department, Faculty of Dentistry, University of Alexandria

c Lecturer of orthodontic, Orthodontic Department, Faculty of Dentistry, Vniversity of Alexandria

\section{INTRODUCTION}

Orthodontics is considered to be a complex problem solving domain. A good example of this is dealing with a large number of factors and treatment options which must be considered when dealing with impacted teeth.

Maverna and Gracco (2007) ${ }^{1}$ defined Impaction as failure of eruption a tooth into the oral cavity within the right time of the normal physiological process.

\footnotetext{
${ }^{1}$ Postgraduate student, Orthodontic Dept, Faculty of Dentistry, Alexandria University

${ }^{2}$ Professor of Orthodontics, Faculty of Dentistry, Alexandria University.

${ }^{3}$ Assistant lecturer of Orthodontics, Faculty of Dentistry, Alexandria University.
} 
Impacted teeth have been a serious problem for orthodontists, the decision whether to extract them or to drag them into occlusion depends on several factors, and require accurate diagnosis and treatment planning and coordination between team of general dentist, orthodontist, periodontist and surgeon. Palatally impacted canines is one of the most common impacted teeth found it occurs in 1 out 100 of people ${ }^{2}, 70-85 \%$ of impacted canines are located in the palate ${ }^{3}$ while $15 \%$ is Jacoby ${ }^{4}$.

The Aim of the studyistodetermine the morphological features of dentition associated with unilateral palatally impacted maxillary canine. And to Predict of the possible local risk factors causing palatal impaction of the maxillary canine.

This will help identifying the subjects with a high risk of unilateral palatal canine impaction facilitating early interception.

\section{Materials and methods:}

The experiment was conducted in the Faculty of Dentistry, Alexandria University. Forty five cone beam records were selected of the Department of Orthodontics, Faculty of Dentistry, Alexandria University or from the CBCT records routinely used for diagnosis of impacted canines according to the following criteria:Inclusion criteria: Patients with unilateral palatally impacted canines aged from 14 to 25 years old.Exclusion criteria: (1) growth according to the case history,(2) Previous orthodontic intervention, only located in the buccal side according to from either the records of the outpatient clinic Congenital facial defects or disease affecting

Congenitally missing maxillary teeth, (4) Systemic diseases affecting growth and eruption.

The entire Cone beam computed tomography scanning data collected were saved in DICOM (digital imaging and communications in medicine) format. Professional medical image software, OnDemand3DApp 1.0.9.3223; Module name [M] DVR was used for tissue segmentation, 3D reconstruction, and volumetric measurement.

The maxilla was separated from the mandible and the mandible was entirely cut and removed from the field of view for facilitation of measurements.

Measurements were made on 3D reconstructed images of the maxillary dentition

The records were divided into two quadrants: the impacted side and the normally erupting side. The following parameters were obtained and compared:

1. The mesiodistal width of each tooth: after viewing the maxilla from occlusal direction oriented by the software and using a 3D ruler for standardized measurments, this was measured from the mesial anatomic contact point to the distal anatomic contact point of each tooth. (Fig 1.)

2. The crown /root ratio of each tooth: the CBCT was oriented to a lateral view by the software, 3D ruler was used and the crown/root ratio was measured by dividing the anatomic height of the crown by the length of the root (mm). (Fig 2.)

3. Interpremolar and intermolar width Volume 55-June 2019 of the upper arch: the interpremolar width 
is the linear measurement between the top of the buccal cusp tips of the right and left maxillary first premolar and the midline viewed from occlusal direction oriented by the software and using a 2D ruler.

The intermolar width is a linear measurement between the mesiopalatal cusp tips of the right and left maxillary first permanent molars and the midline viewed from occlusal direction. (Fig3.)

4. Arch perimeter: this was measured from the occlusal view using a 3D curve line from the midline to the mesial contact point of the first permanent molars on both sides and compared to each other. (Fig4.)

5. Angulation and morphology of the root of the impacted canine compared to the contralateral normally erupting canine: by measuring the angle between the long axis of the crown and the long axis of the root after orienting the canine in a buccal view and long axis of the crown perpendicular to the floor, in addition to inspection of dilacerations. (Fig5. \& Fig6.)

6. The volume of the impacted canine compared to the contralateral normally erupting canine: this was measured using the software $\left(\mathrm{mm}^{3}\right)$ after separating each canine separately and removing any overlaying bone. . (Fig7. \& Fig8.)

All measurements on CBCT were made twice by the same examiner with one week interval between the two measurements. If the difference between the two measurements is apparent, a third reading will be made and the aberrant one discarded. The mean of the two closest measurements was used in the calculations.

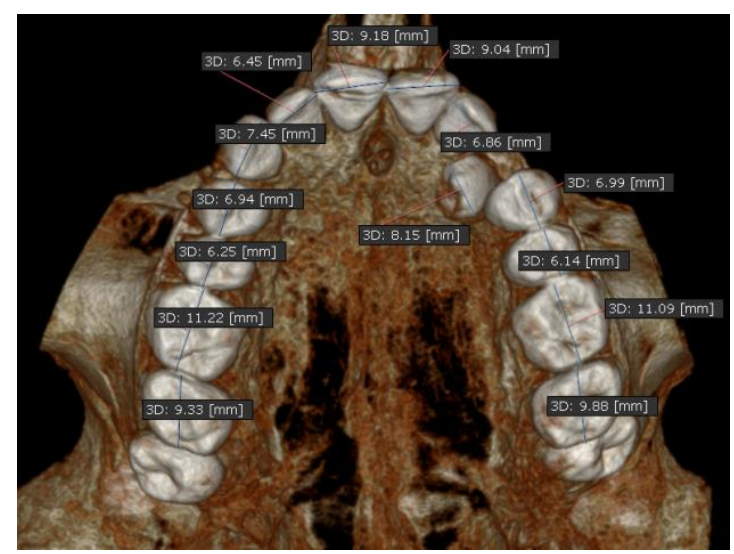

Figure 1 Measuring mesiodistal dimensions of the teeth

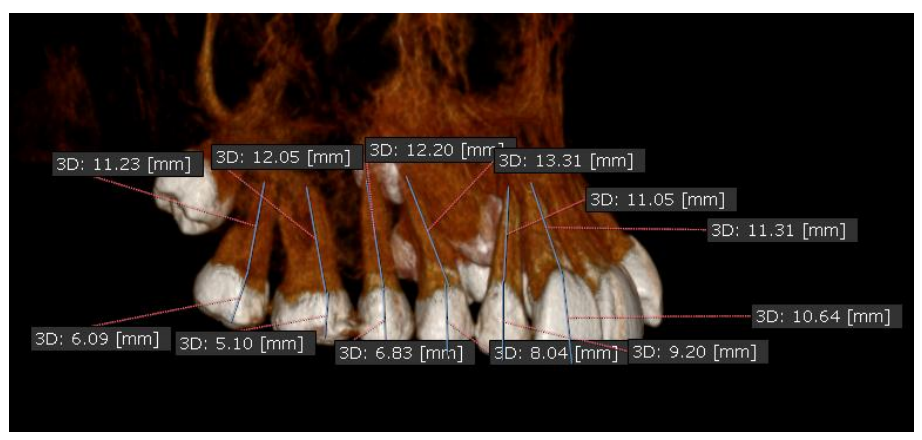

Figure 2 Measuring crown/root ratio of the teeth

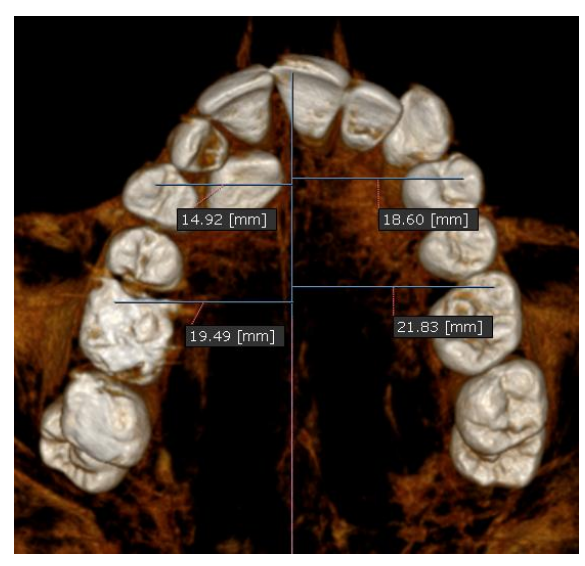

Figure 3 Measuring interpremolar and intermolar distances 


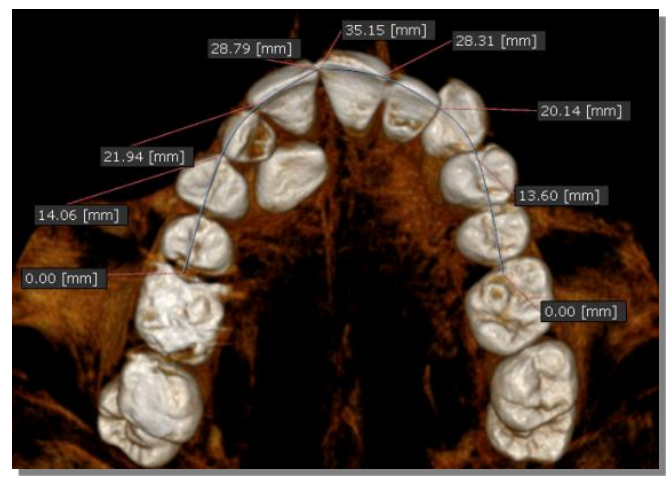

Figure 4 Measuring arch perimeter on both sides.

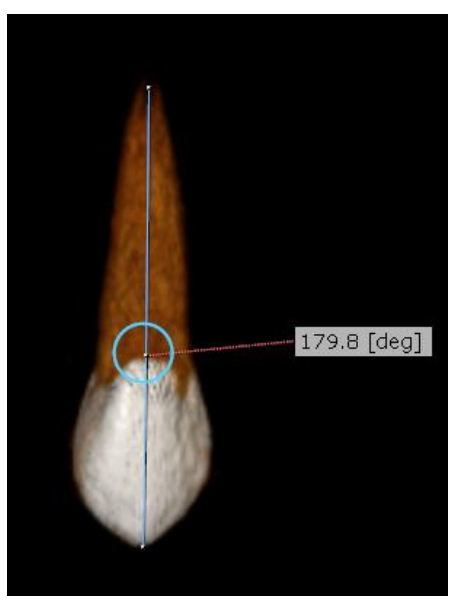

Figure 5 Measuring canine angulation (root long axis in relation to crown long axis)

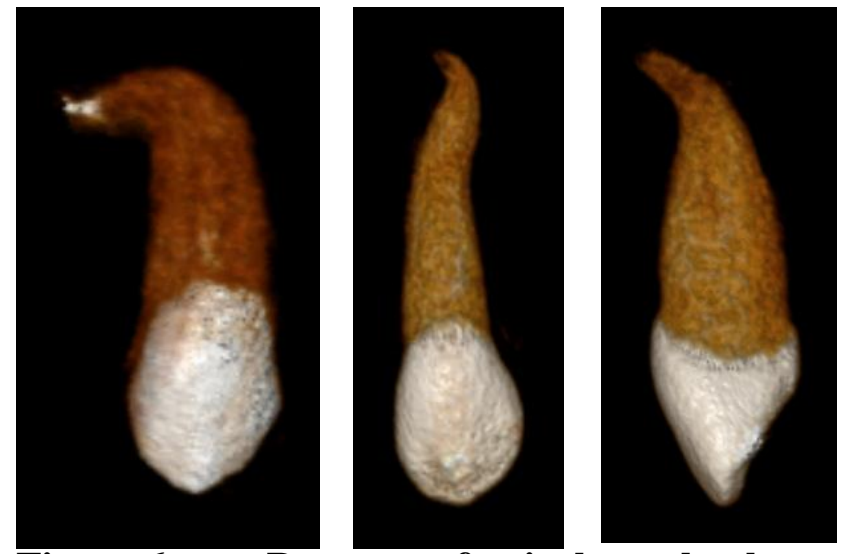

Figure $6 \quad$ Presence of apical root hook
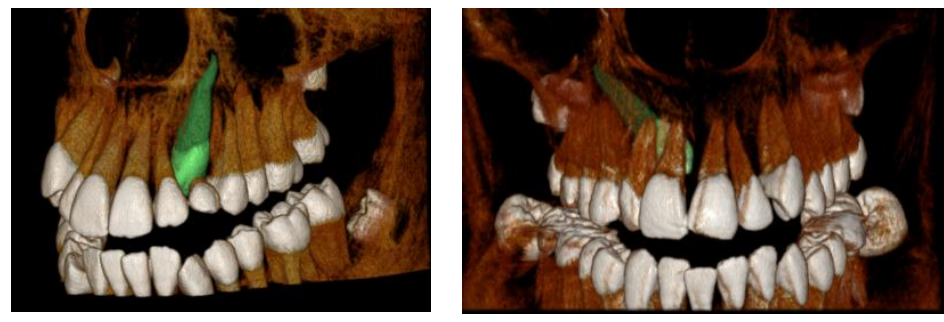

Figure 7 Measuring canine volume on the impacted side
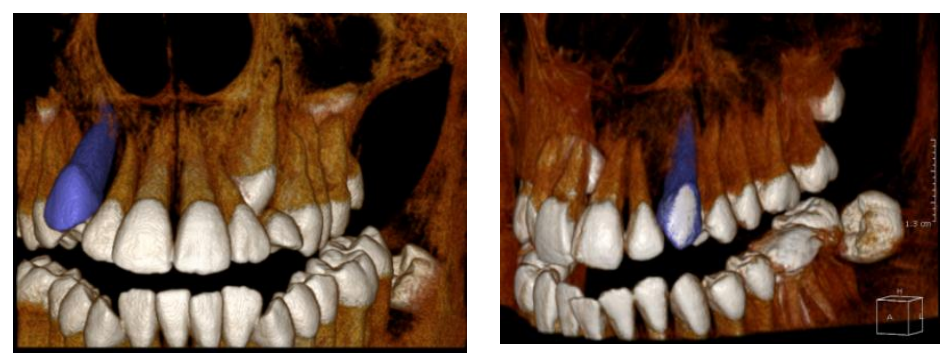

Figure 8 Measuring canine volume on the normally erupting side

\section{Sample size}

By adopting a power of $95 \%$ to detect the difference in canine volume as a primarily outcome of 0.776 (medium-sized standardized effect size $)^{5}$, and level of significance $95 \%$ $(\alpha=0.05)$, the minimal required sample size was found to be $\mathbf{2 4}^{6}$. When we adopt a smaller standardized effect size equal to 0.50 the minimal required sample size was found to be 45. Sample size do not need to be increased to control for attrition (withdrawal) bias ${ }^{7}$. Consecutive samplings were used till reaching the required sample size.The sample size was calculated using GPower version 3.1.9.2. ${ }^{8}$ 


\section{Results:}

This study was carried out on 45 cone beam X-rays of patients with unilateral palatally impacted canines. The mean age was 20.38 years ranging from 14 to 26 years. 34 patients were females and 11 were males representing $75.6 \%$ and $24.4 \%$ respectively.

When comparing the mesiodistal dimensions of the teeth on the impacted side and normally erupting side, it was found that there was no statistically significant difference between the two sides.(fig 9)

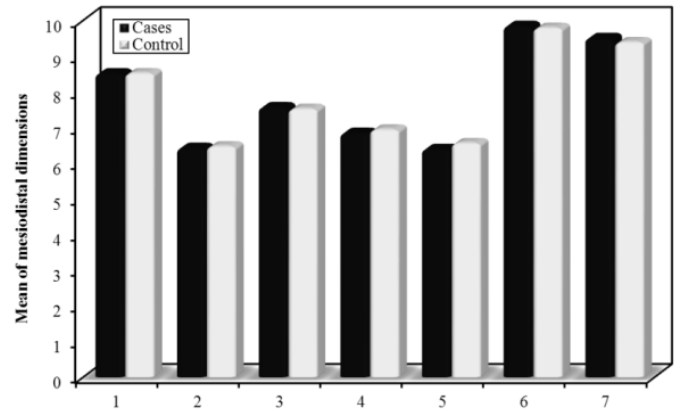

Figure 9 Comparison between the two studied periods according to mesiodistal dimensions

When comparing the crown/root ratio of the teeth on the impacted side and normally erupting side, it was found that only crown/root ratio of the maxillary lateral incisor and canines showed significantly larger crown root ratio on the impacted side. (Table I)

Table I Comparison between the two sides according to mesiodistal dimensions.

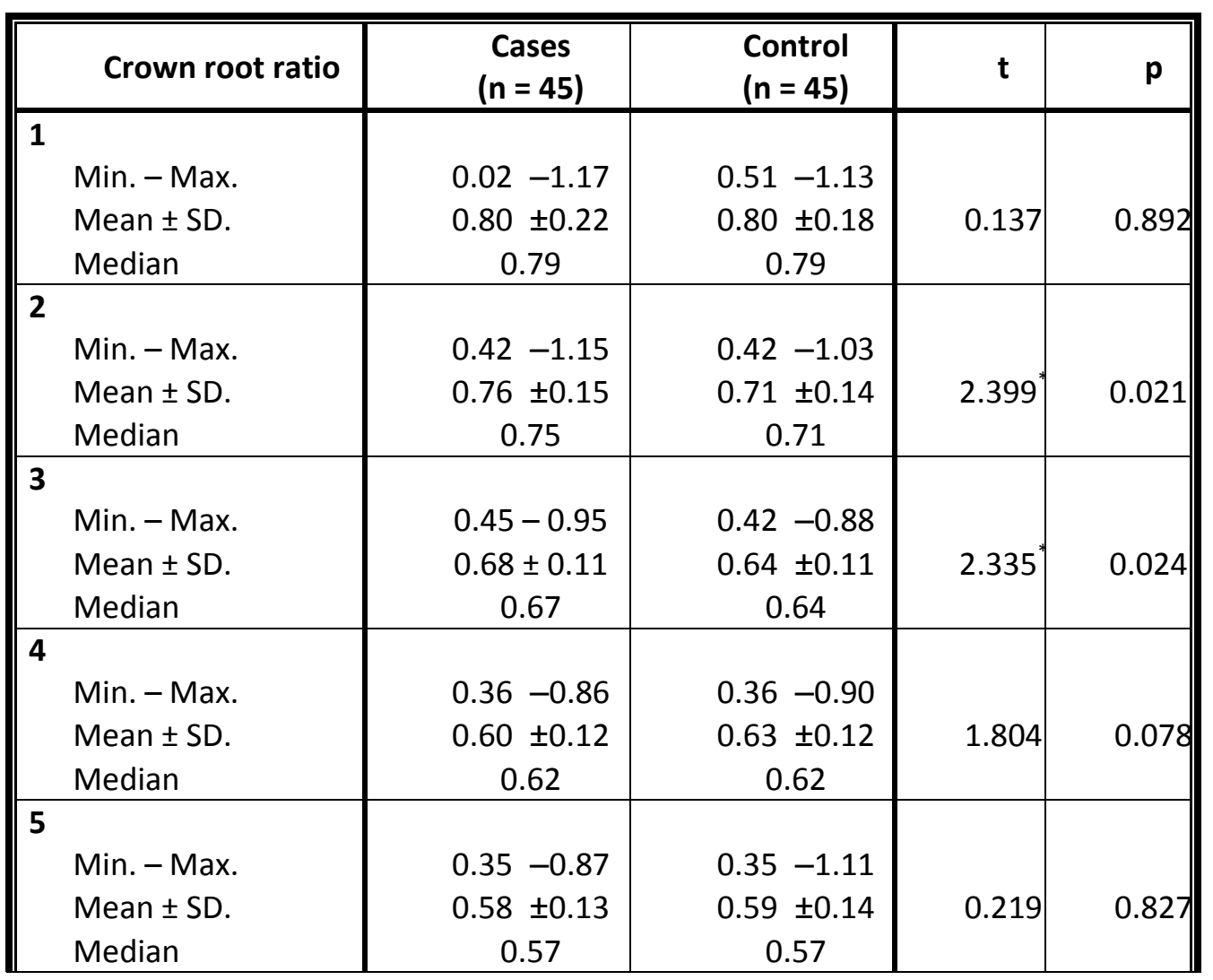




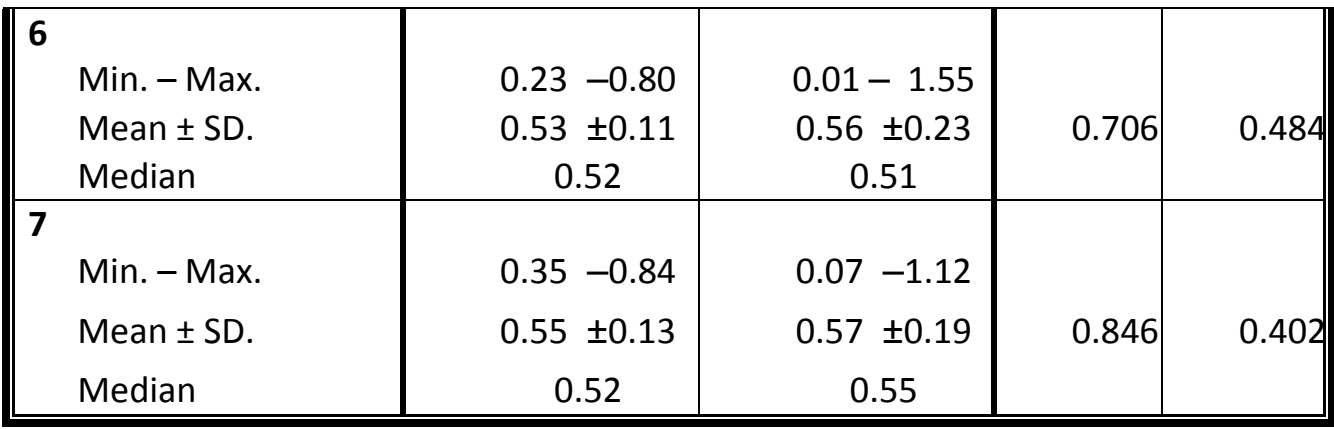

\section{t: Paired t-test}

$\mathrm{p}$ : $\mathrm{p}$ value for comparing between the studied periods

*: Statistically significant at $\mathrm{p} \leq 0.05$

The crown and root lengths of the lateral incisor and canine were measured separately, The root of the lateral incisor was shown to be significantly shorter on the impacted side (Table II), while the crown of the canine was shown to be significantly taller (Table III).

Table II Comparison between crown lengths of lateral incisor and canine of two sides

\begin{tabular}{|c|c|c|c|c|}
\hline Crown & $\begin{array}{c}\text { Cases } \\
(\mathbf{n = 4 5})\end{array}$ & $\begin{array}{c}\text { Control } \\
(\mathbf{n = 4 5})\end{array}$ & $\mathbf{t}$ & $\mathbf{p}$ \\
\hline Lateral incisor & $5.50-11.70$ & $6.56-10.86$ & & \\
Min. - Max. & $8.88 \pm 1.39$ & $8.93 \pm 1.13$ & 0.453 & 0.653 \\
Mean \pm SD. & 9.31 & 9.18 & & \\
Median & $7.40-12.66$ & $6.0-11.76$ & & \\
\hline Canine & $9.86 \pm 1.20$ & $9.55 \pm 1.33$ & 2.110 & 0.041 \\
Min. - Max. & 10.0 & 9.78 & & \\
Mean \pm SD. & & & \\
Median & &
\end{tabular}

\section{t: Paired t-test}

$\mathrm{p}$ : $\mathrm{p}$ value for comparing between the studied periods

Table III Comparison between root lengths of lateral incisor and canine of two sides

\begin{tabular}{|c|c|c|c|c|}
\hline Root & $\begin{array}{c}\text { Cases } \\
(n=45) \\
\end{array}$ & $\begin{array}{l}\text { Control } \\
(n=45)\end{array}$ & $\mathbf{t}$ & p \\
\hline $\begin{array}{l}\text { Min. - Max. } \\
\text { Mean } \pm \text { SD. } \\
\text { Median } \\
\end{array}$ & $\begin{array}{c}7.27-15.22 \\
11.94 \pm 2.08 \\
12.31 \\
\end{array}$ & $\begin{array}{c}10.21-16.0 \\
12.82 \pm 1.64 \\
13.10 \\
\end{array}$ & 3.048 & 0.004 \\
\hline $\begin{array}{l}\text { Min. - Max. } \\
\text { Mean } \pm \text { SD. } \\
\text { Median }\end{array}$ & $\begin{array}{c}10.83-18.70 \\
14.70 \pm 1.84 \\
14.57\end{array}$ & $\begin{array}{c}11.70-18.78 \\
15.08 \pm 1.86 \\
15.18\end{array}$ & 1.300 & 0.201 \\
\hline
\end{tabular}

\section{t: Paired t-test}

$\mathrm{p}: \mathrm{p}$ value for comparing between the studied periods

*: Statistically significant at $\mathrm{p} \leq 0.05$ 
Interpremolar width was significantly less on the case side than the control side while the intermolar width has no statistically significant difference between two sides. Table IV

Table IV Comparison between the two sides according to maxillary transverse dimensions.

\begin{tabular}{||c|r|r|r|r||}
\hline Arch dimensions & $\begin{array}{r}\text { Cases } \\
(\mathbf{n}=\mathbf{4 5})\end{array}$ & $\begin{array}{r}\text { Control } \\
(\mathbf{n}=45)\end{array}$ & $\mathbf{t}$ & $\mathbf{p}$ \\
\hline Interpremolar & $15.36-30.93$ & $15.55-29.3$ & & \\
Min. - Max. & $22.78 \pm 4.38$ & $23.37 \pm 3.88$ & 2.085 & 0.043 \\
Mean \pm SD. & 21.80 & 23.76 & & \\
Median & $19.43-75.91$ & $21.09-74.31$ & & \\
\hline Intermolar & $29.32 \pm 8.71$ & $29.36 \pm 8.27$ & 0.143 & 0.887 \\
Min. - Max. & 29.98 & 29.99 & & \\
Mean \pm SD. & & & & \\
Median & & & & \\
\hline
\end{tabular}

\section{t: Paired t-test}

Z: Wilcoxon signed ranks test

$\mathrm{p}$ : $\mathrm{p}$ value for comparing between the studied periods

*: Statistically significant at $\mathrm{p} \leq 0.05$

Arch perimeter was found to be significantly smaller on the case side than the control side. Angulation of the canines was found to be insignificantly more divergent on the control side than the case side. The volume of the canine was found to be significantly larger on the case side than the control side. (fig 10)

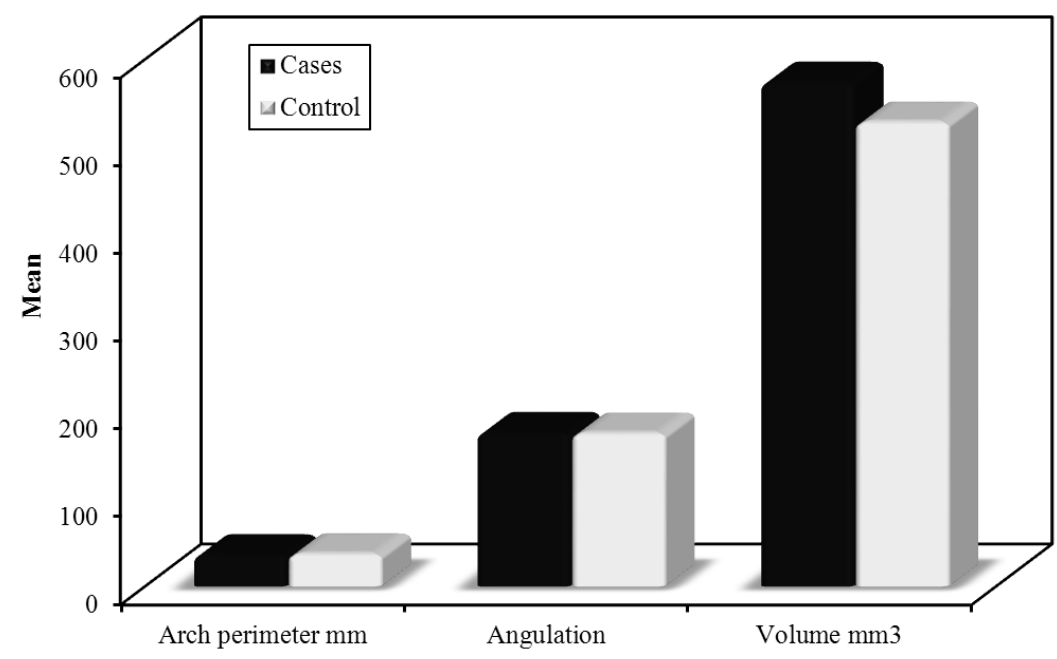

Figure 9 Comparison between the two studied periods according to Arch perimeter mm, Angulation and Volume mm3 
Palatal canine displacement has been a subject of orthodontic considerations since early stages. Failure of canine to erupt into its normal position has several reasons in our study we are concerned about the morphological features of the canine and the surrounding dentition so as to determine the common risk factors causing palatal displacement of the canine.

Several studies worked on the morphological etiological factors of canine impaction(Abdel-Salam, El-Badrawy, \& Tawfik, 2012; Brenchley \& Oliver, 1997; Kim, Hyun, \& Jang, 2017; Oliver, Mannion, \& Robinson, 1989) most of them were focused on the size and shape of lateral incisor, only few studies related the whole maxillary dentition morphological features to the canine impaction 12 cone beam $\mathrm{x}$-rays were used to evaluate root lengths, shape and volume of canines.

Our study was designed as a split mouth retrospective study on 45 cone beam x-rays. The impacted side served as case and the normally erupting side as the control, data were collected, compared and analyzed.

\section{Difference in the mesiodistal} width of the maxillary teeth between the impaction and comparison sides

When comparing the mesiodistal width of maxillary teeth it showed that there is no statistically significant difference between the two sides.

Our results came in line with those of AlNimri \& Gharaibeh who stated that The mesiodistal widths of the maxillary teeth were not significantly different in the impaction and comparison groups. ${ }^{12}$
Becker, Sharabi, \& Chaushu, agreed with our results they stated that no difference between the size of teeth on affected and unaffected sides, in unilateral palatally displaced canines. ${ }^{13}$

Oliver et al disagreed with our results. They stated that the maxillary lateral incisor adjacent to an impacted canine is generally smaller than the contra- lateral incisor. This contradiction may be due to ethnic origin as he they made their study on Caucasian population. 10

These results were in disagreement with those of Mossey, Campbell, \& Luffingham they concluded thatsubjects with narrower than average maxillary lateral incisor crowns are more at risk of palatal displacement of the maxillary canine. ${ }^{14}$

\section{Difference in the crown/root ratio} of the maxillary teeth between the impaction and comparison sides

All the results showed no statistically significant difference on crown/root ratio between the impacted side and the normally erupting side except for the lateral incisor and canine which showed increased crown/root ratio.

Further analysis of the data for the lateral incisor and the canine were made showed decreased root length of the lateral incisor and increased crown length of the canine on the impacted side.

Our results came into agreement with those findings of Kim et al. in 2017 who stated that the length and volume of the maxillary lateral incisor's root were significantly smaller on theimpaction side compared with the normal eruption side, and the width and 
volume of the crown were significantly greater on the impaction side compared with the normal eruption side This indicates that there is a high correlation between maxillary canine impaction and smaller lateral incisor root sizes. $^{5}$

This may lead to lack of canine root guidance which leads to canine impaction.

Our results showed if the root of the lateral is less than $\leq 11.85 \mathrm{~mm}$ or the crown of the canine more than $>10 \mathrm{~mm}$ this may lead to occurrence of the anomaly.

A systematic review done by Schroder et al., in 2018 stated that root resorption in maxillary incisors was correlated with their contact with maxillary canines during eruption. Delayed eruption or treatment of impacted canines may lead to resorption of the adjacent lateral and central incisors. All root levels and surfaces of teeth associated with impacted maxillary canines can be resorbed to different levels of severity, but the apical one-third with slight resorption is the most common. ${ }^{15}$

This may conflict our results that root resorption of the lateral incisor was secondary to palatal canine displacement not a predisposing factor.

\section{Difference between two sides according to maxillary transverse dimensions.}

Our results revealed statistically different narrower arch dimension in the anterior (interpremolar) maxillary transverse dimension in the impacted side than the normally erupting side, while it showed no statistical difference in the posterior (intermolar) maxillary transverse dimension between the impacted side and the normally erupting side.
These results were similar to those from McConnell et $\mathrm{al}^{16}$, who reprted that subjects with maxillary canine impactions had transverse maxillary deficency exhibited in the anterior portion of the dental arch. No differences were detected between the groups' intermolar widths.

These results contradicted the findings of Langberg \& Peck who stated that arch width measurements of palataly displaced canines subjects compared with a control group of age and gender matched orthodontic patients indicate that there is no statistically significant difference in the anterior and posterior maxillary arch width between palatlly displaced canines subjects and a sample of control subjects. ${ }^{17}$

This conflict may be due to difference in study design, as they had two groups and compared iterpremolar and intermolar distances between impacted canine casts to control group with normally erupting pattern , unlike our study as w had a split mouth design comparing two sides. Aslo it may be may be due to difference in ethnic origin as the sample was made on white people from northeastern United States while ours was made on egyptian population.

Kim, Hyun, \& Jang studied the relationship between the position of impacted maxillary canines and the morphology of the maxilla ${ }^{18}$. They supported the findings of McConnel et al. and concluded that the shape of the maxillary arch was narrower and longer in the palatally impacted canine group compared with the buccally impacted canine group, and the palatally impacted canine group had a deeper palatal vault than did the buccally impacted canine group. 


\section{Difference between the two sides according to arch perimeter.}

Several authors have been commented on the existence of palatal canine impaction in association with arch perimeter deficiency and spaced dentition.(Jacoby, 2013;Stellzig, Basdra, \& Komposch, 1994) In our study arch perimeter was found to be significantly narrower on the case side than the control side.

Our results showed that an interpremolar distance of $\leq 20.55$ would lead to occurrence of the anomaly on this side.

In contrast, Al-Nimri and Gharaibeh ${ }^{12}$ found no statistically significant difference in the degree of crowding between that palatal canine impaction group and their matched comparisons. However they stressed that these results do not necessarily contradict the earlier finding that the canines becomes palatally impacted by crossing back to the palatal side if extra space is available in the maxilla ${ }^{4}$, because crowding is a diagnosis related to inadequate space to accommodate the aggregated mesiodistal diameters of the crowns of the teeth. By contrast, the distance between the roots of the same teeth may become progressively larger, providing more space mesiodistally in the root area, which is where the impacted canine is located.

\section{Difference between the two sides according to angulation of the canines.}

In our study we measured the angulation of the canines, between the long axis of the crown and the long axis of the root was found to be insignificantly more divergent on the control side than the case side.
The average value of the angle between the tooth axis and the occlusal plane was lower than the value of the contralateral well-aligned canine. $^{20}$

Using three-dimensional CBCT imaging, one study(Alqerban, et al, 2015) found that angle of the canine to adjacent lateral incisor angle in the coronal view to be an excellent predictor for canine impaction.

Angle between the long axis of canine and dental midline there were no statistically significant differences between impacted and erupted canines. $^{23}$

\section{Difference between the two sides according to volume of the canines.}

In our study the volume of the canine showed to be significantly larger on the case side than the control side.

A cut off point of $>539.25 \mathrm{~mm}^{3}$ of the volume of the canine would lead to occurrence of the anomaly on this side.

This was approved by Kim et al. as they concluded thatthe width and volume of the crown were significantly greater on the impaction side compared with the normal eruption side ( $\mathrm{P} \quad 1 / 4 \quad 0.020$ and $\mathrm{P}, .0001$, respectively). This indicates that there is a high correlation between maxillary canine impaction and greater crown sizes. ${ }^{5}$

Difference between the two sides according to presence of apical hook of the canines.

On observation of the apical hook of the canine (Vithanage et al, 2017) found that $36.4 \%$ of palatally impacted maxillary canines had a hook. In our study, $11.1 \%$ of palatally impacted canines had a hook. $6.7 \%$ of the 
patients had apical hooks on the normally erupting side and, $8 \%$ had apical hooks on both sides.

Standerwick ${ }^{25}$ hypothesized that tooth root dilaceration and flexion resulted from tooth root sheath displacement caused by gradients of plasticity in the alveolar bone.As a tooth is erupting or experiences delayed eruption, other relative dentoskeletal alterations are occurring, such as mesial drift of the dentition and remodeling growth of the maxilla. (fig 11)

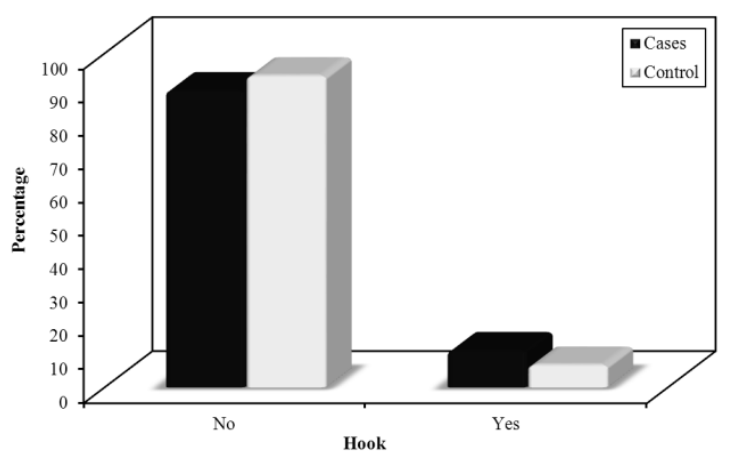

Figure 11: Comparison between the sides according to hook.

\section{Conclusion:}

1. The mesiodistal widths of the maxillary teeth were not significantly different in the impaction and comparison groups.

2. No statistically significant difference on crown/root ratio between the impacted side and the normally erupting side except for the lateral incisor and canine which showed increased crown/root ratio

3. Statistically narrower arch dimension in the anterior (interpremolar) maxillary transverse dimension in the impacted side than the normally erupting side, while it showed no statistical difference in the posterior (intermolar) maxillary transverse dimension between the impacted side and the normally erupting side.

4.

rch perimeter was found to be significantly narrower on the case side than the control side.

5. The angulation of the canines, between the long axis of the crown and the long axis of the root was found to be insignificantly more divergent on the control side than the case side.

6. The volume of the canine showed to be significantly larger on the case side than the control side.

7. $11.1 \%$ of palatally impacted canines had a hook. $6.7 \%$ of the patients had apical hooks on the normally erupting side and, $8 \%$ had apical hooks on both sides.

Thus a narrower interpremolar width, increased canine volume, shorter root of lateral incisor and increased length of canine crown are contributing factors for impaction of the canine.

\section{Refrences:}

1. Maverna, R. \& G. Different diagnostic tools for the localization of impacted maxillary canines: clinical considerations. Prog Orthod. 2007;349-83.

2. Dachi SF, Howell F V. A survey of 3,874 routine full-mouth radiographs. II. A study of impacted teeth. Oral Surgery, Oral Med Oral Pathol. 1961;14(10):1165-9.

3. Berry HM. Positional Variations of the Impacted Upper Canine. A Clinical and Radiologic Study. Oral Burg, Oral Med Oral Path. 1981;245.

4. Jacoby H. The etiology of maxillary canine impaction: Part 1. Bull \#21. 1983;(April):1-10. 
5. Kim Y, Hyun HK, Jang KT. Morphological relationship analysis of impacted maxillary canines and the adjacent teeth on 3-dimensional reconstructed CT images. Angle Orthod. 2017;87(4):590-7.

6. Charan J, Biswas T. Review Article How to Calculate Sample Size for Different Study Designs in Medical Research ? Indian J Psychol Med. 2013;35(2).

7. Pannucci CJ WE. Identifying and avoiding bias in research. Plast Reconstr Surg. 2010;619-25.

8. Lang AG BFFEE. G*Power 3: A flexible statistical power analysis program for the social, behavioral, and biomedical sciences. In: Behavior Research Methods. 2007. p. 17591.

9. Brenchley Z, Oliver RG. Morphology of anterior teeth associated with displaced canines. Br J Orthod. 1997;24(1):41-5.

10. Oliver RG, Mannion JE, Robinson JM. Morphology of the maxillary lateral incisor in cases of unilateral impaction of the maxillary canine. Br J Orthod. 1989;16(1):9-16.

11. Abdel-Salam E, El-Badrawy A, Tawfik AM. Multi-detector dental CT in evaluation of impacted maxillary canine. Egypt J Radiol Nucl Med. 2012;43(4):527-34.

12. Al-Nimri K, Gharaibeh T. Space conditions and dental and occlusal features in patients with palatally impacted maxillary canines: An aetiological study. Eur J Orthod. 2005;27(5):461-5.

13. Becker A, Sharabi S, Chaushu S. Maxillary tooth size variation in dentitions with palatal canine displacement. Eur J Orthod. 2002;24(3):313-8.
14. Mossey PA, Campbell HM, Luffingham JK. The palatal canine and the adjacent lateral incisor: a study of a west of Scotland population. $\mathrm{Br} \quad \mathrm{J}$ Orthod. 1994;21(2):169-74.

15. Schroder AGD, Guariza-Filho O, de Araujo CM, Ruellas AC, Tanaka OM, Porporatti AL. To what extent are impacted canines associated with root resorption of the adjacent tooth?: A systematic review with meta-analysis. J Am Dent Assoc. 2018;149(9):765-777.e8.

16. McConnell, TL; Hoffman, DL; Forbes D et al. Maxillary canine impaction in patients with transverse maxillary deficiency. J Dent Child. 1996;63(3):190.

17. Langberg BJ, Peck S. Adequacy of maxillary dental arch width in patients with palatally displaced canines. Am J Orthod. 2000;220-3.

18. Kim Y, Hyun $\mathrm{H}$, Jang $\mathrm{K}$. Interrelationship between the position of impacted maxillary canines and the morphology of the maxilla. Am J Orthod Dentofac Orthop. 2012;141(5):556-62.

19. Stellzig A, Basdra EK, Komposch G. The etiology of canine tooth impaction--a space analysis. Fortschr Kieferorthop. 1994;55(3):97-103.

20. Gavel V, Dermaut L. The effect of changes in tooth position of unerupted canines on cephalograms. Eur J Orthod. 2003;25(1):49-56.

21. Malik D e. S, Fida M, Sukhia RH. Correlation between radiographic parameters for the prediction of palatally impacted 
maxillary canines. J Orthod. 2019;

22. Alqerban A, Jacobs R, Fieuws S, Willems G. Radiographic predictors for maxillary canine impaction. Am J Orthod Dentofac Orthop. 2015;147(3):345-54.

23. Laurenziello M, Montaruli G, Gallo C, Tepedino M, Guida L, Perillo L, et al. Determinants of maxillary canine impaction: Retrospective clinical and radiographic study. J Clin Exp Dent. 2017;9(11):e1304.
24. Vithanage P, Shihanika K, Olive RJ, Monsour P. Morphology of palatally impacted canines: A case-controlled cone-beam volumetric tomography study. Am J Orthod Dentofac Orthop. 2017;151(2):357-62.

25. Standerwick RG. A possible etiology for the dilaceration and flexion of permanent tooth roots relative to bone remodeling gradients in alveolar bone. Dent Hypotheses. 2014;5(1):7. 